\title{
Patients with epilepsy care experiences: comparison between services with and without an Epilepsy Specialist Nurse (SENsE Study)
}

\author{
Please cite as Higgins, A., Downes, C., Varley, J., Tyrell, E., Normand, C., Doherty, C.P., Begley, C., Elliott, N. \\ (2018). Patients with epilepsy care experiences: Comparison between services with and without an epilepsy \\ specialist nurse. Epilepsy \& Behavior, 85:85-94. doi: 10.1016/j.yebeh.2018.05.038.
}

\section{Please note that some changes may have been made to the final paper above}

\begin{abstract}
The aim of this study was to determine whether there were differences in experiences of care, satisfaction with care and quality of life between those who were in receipt of care from a service with an epilepsy specialist nurse (ESN) and those who were receiving care from a service that did not include an ESN. A comparative design was used which involved the completion of a confidential, self-completed survey. The survey was administered to a non-probability convenience sample of patients with epilepsy who were attending services with an ESN ( $n=244)$ and services where the treatment team did not include an ESN ( $n=261)$ from each of the four health areas in Ireland. This study found that, in comparison to people with epilepsy (PWE) who attended a service without an ESN, PWE who attended a service with an ESN reported receiving a greater amount of information, being more involved in their care, perceived care to be better coordinated, had greater confidence in the information provided and greater comfort in discussing issues with an ESN. They also reported higher rates of satisfaction with the emotional and practical support offered. Thus, it may be concluded that models of care involving the input of ESNs enhance the quality of epilepsy care and care processes. The findings also emphasise the need to have an ESN as part of the multidisciplinary team.
\end{abstract}

Keywords: Epilepsy, Specialist Nurse, Advanced Practice, Impact, Comparative study, Service delivery

\section{Introduction}

Epilepsy is a common neurological condition with a prevalence estimated to be between 510 per 1,000 persons [1]. Most people with epilepsy (PWE) experience long-term remission and manage their epilepsy through medication, once the most effective regimen is followed. However, a significant number experience ongoing problems in the form of breakthrough seizures or prolonged uncontrolled convulsive activity which have profound implications for their physiological and psychological well-being as well as other aspects of their lives, including social, educational and employment [2]. As epilepsy is considered a chronic disease, the authors assert that its management requires a shift from a reactive health care system that views the patient as a passive recipient to a model that is proactive and supports the patient to develop knowledge and skills in self-management. 
Despite the importance of access to timely co-ordinated care and early and accurate diagnosis [3], the literature documents many gaps and unmet needs in the care and treatment of PWE. In a systematic review of satisfaction with care, it was found that PWE are least satisfied with communication, knowledge and perceived skills of health care providers, with a significant number of PWE expressing dissatisfaction with the information provided to them [4]. Studies indicate that, due to time constraints and/or lack of expertise, doctors, neurologists and other professionals do not comprehensively address with PWE essential elements of care such as diagnoses, treatments, drug interactions and side-effects, as well as the psychosocial implications of epilepsy $[5,6,7,8]$. Compounding this lack of information is the reticence PWE experience around asking questions of clinicians for fear of wasting their time [5,8]. A more recent systematic review of unmet needs identified challenges that PWE experience in the availability, accessibility and acceptability of services [9]. In terms of availability, a lack of specialist services, long waiting times and insufficient consultation time was reported. Cost of care and challenges around transport were the main issues that impacted on accessibility, with culture, language and interpreter issues being the primary issues affecting acceptability. Similarly in Ireland, studies of PWE echo international findings, reporting delays in accessing specialist services, a lack of co-ordinated care and information sharing, inadequate follow-up care and a belief that general practitioners have insufficient knowledge of epilepsy $[10,11]$. Given the evidence of the impact of poor quality epilepsy care on mortality, morbidity and healthcare costs, finding a model of care that addresses epilepsy care deficits is critical. The inclusion of Epilepsy Specialists Nurses within the multidisciplinary team has been proffered as a solution to address some of these unmet needs and challenges [12]. The overall aim of the study reported in the paper was to evaluate the impact of ESN care on PWE's experiences of care, satisfaction with care and quality of life. The core objective was to determine whether there were differences in experiences of care, satisfaction with care and quality of life between those who were in receipt of care from a hospital-based epilepsy service with an ESN and those who were receiving care from an epilepsy/neurology service that did not include an ESN role.

\section{Epilepsy specialists nurses}

Internationally, the role of the epilepsy specialist nurse (ESN) is recognised as an integral part of the epilepsy multidisciplinary care team. The role is said to encompass facilitating PWE to access services, supporting the coordination of care and providing information, education and support to PWE and their families $[13,14]$. In qualitative studies that have explored the ESN role from the perspective of PWE, the role has been endorsed for providing continuity of care $[6,15,16,17]$, increasing the accessibility of care $[8,18,17]$ and facilitating greater opportunity to access information and advice $[7,18,16]$. In this regard, ESN care is said to result in enhanced knowledge of epilepsy among PWE and a greater ability to self-manage the condition $[7,8,17]$. The effectiveness of ESN care in terms of the 
provision of information was demonstrated in Ridsdale et al.'s study which showed that more advice was provided on epilepsy through nurse-run clinics [19]. Pfäfflin et al.'s study [12] also showed significant improvements in epilepsy knowledge, satisfaction with information and support, and information seeking in the ESN group in comparison to the control group. Nevertheless authors of two systematic reviews conclude that the evidence in support of the effectiveness of ESN care is mixed at best, and is not robust enough to assert that ESN care results in better care or outcomes compared to those receiving standard treatment $[20,21]$.

In Ireland, in recognition of the relationship between quality services and health outcomes, the National Clinical Care Programme in Epilepsy (NCPE) [22] was charged with addressing the historic deficits in epilepsy care. As part of a range of policy and system changes to improve access to person centred epilepsy care the NCPE recommended that every PWE have access to an ESN. In Ireland an ESN has specialist education and expertise in epilepsy, plays a key role in the management and support of people with epilepsy across primary, secondary and tertiary care and may be working as a clinical nurse specialist (CNS) or an advanced nurse practitioner (ANP). The CNS is defined as a nurse who works in an area of specialist clinical practice, works closely with medical and para-medical colleagues, educates colleagues, improves the quality of patient care through audit and research [23]. An ANP is defined as a nurse who is an autonomous practitioner, responsible for advanced levels of decision making, managing a patient caseload, demonstrates clinical and professional leadership and advances clinical practice through research. An ANP holds a Master's degree in nursing or a higher degree which contains substantial modules related to advanced practice in the specific area of expertise [24].

Given the ESN role is said to focus not only on clinical/medical aspects of epilepsy but also on providing information and support to patients through educational and therapeutic work to enable them to self-manage and cope with the challenges presented in every aspect of life, be it social, educational or vocational, it was important to assess how well this role is responding to the holistic needs of PWE. With a view to informing future developments in relation to the role in Ireland, and supported by Epilepsy Ireland and the Health Research Board, the Specialist Epilepsy Nurse(s) Evaluation [SENsE] study set out to identify the role and cost-effectiveness of the ESNs and to evaluate their impact on patient care. This paper reports some aspects of the findings and focuses on differences in care experiences, satisfaction with care and quality of life (QoL) between PWE attending a service with an ESN and those attending a service that did not include an ESN.

\section{Methods}

\subsection{Research design}


A comparative, cross-sectional survey design was adopted to achieve the objective of determining differences in PWE's experiences of care between services with and without ESNs.

\subsection{Survey}

Data for the study were collected using a confidential, self-completed survey. This method was selected as it is a relatively easy and cost-effective means of obtaining structured information from participants, while its anonymity minimises the potential for socially desirable responses $[25,26]$.

The survey collected information on patients' demographic characteristics and epilepsy profile, and examined patients' experiences of the care provided in relation to information provided on epilepsy (21 items), involvement in care (6 items), co-ordination of care (4 items), continuity of care ( 3 items), comfort with and confidence in care (4 items), whether treated with dignity and respect ( 2 items), impact of care on health and well-being ( 1 item), and satisfaction with emotional and practical support ( 2 items). The 21 items on information provided were focused on the nature of epilepsy and their own epilepsy ( 4 items); medical aspects of epilepsy ( 9 items); social aspects of epilepsy; ( 3 items) and safety aspects of epilepsy ( 4 items). One item related to information on pregnancy and was only applicable to the female participants.

Some of the items include in the questionnaire were adapted from the survey used within the SCAPE study $[27,28,29,30]$, a national evaluation of clinical specialist and advanced nurse and midwife practitioners in Ireland, while others were developed by the research team. People with epilepsy were asked to rate their experience of care provided by the ESN, or, in the case of the non-ESN sites, the provision of care from health practitioners, which is mainly neurology specialists or medical consultants with expertise in epilepsy. Most questions contained likert response categories ranging from 1 ('strongly disagree') to 5 ('strongly agree'), with the exception of the two questions on practical and emotional support which used a ten point scale ranging from 1 ('Not at all satisfied') to 10 ('completely satisfied'). Higher scores indicated a more positive perception of the issue being measured.

The survey also included the QOLIE-10-P, an adaptation of the QOLIE-10 [31] to assess the impact on patients' quality of life. The QOLIE-10-P requests participants to rate the degree to which a number of epilepsy-related issues have impaired their quality of life over the past 4 weeks. Items include Seizure Worry, Overall Quality of Life, Emotional Well-Being, Energy/Fatigue, Cognitive Function, Medication Effects, Social Function, and Overall Distress. The final score ranges from 0 to 100 with a higher score indicating better quality of life. Permission to use copyright questionnaires was obtained before use. 


\subsection{Sample and Recruitment}

As there was no national database of PWE, the survey was administered to a nonprobability convenience sample of patients with epilepsy who were attending services with an ESN and services where the treatment team did not include an ESN from each of the four health areas in Ireland. To be included in the survey patients had to have: a diagnosis of epilepsy; be aware of their diagnosis; be attending a service (with or without an ESN) for one year or more; be over 18 years of age and not have an intellectual disability or dementia to the level that they would not be able to self-complete the survey.

In order to recruit the sample, eight hospitals from the different health areas in Ireland were purposefully selected (three hospitals with ESNs and five hospitals that did not have an ESN as part of the team). Soon after the study commenced, one of the non-ESN sites appointed an ESN, and data collection had to cease in that site. The majority of the data for the nonESN sample were thus collected from four hospital sites. With the permission of medical consultants, research assistants attended a number of epilepsy or neurology clinics in the eight hospitals when PWE were attending for follow-up review. To recruit participants the researchers distributed a survey pack which contained survey and written information about the study. They also gave the person a verbal explanation and answered any questions asked. Potential participants were given the option of completing the survey while waiting at the clinic or completing and returning it at a later time using the pre-paid postal envelope supplied.

\subsection{Data collection}

Data for the study were collected over a two year period in 2014-2016.

\subsection{Data analysis}

Data were entered into Statistical Package for the Social Sciences (SPSS), version 21 [32]. The data were analysed using descriptive statistics, namely frequencies, percentages, means and standard deviations. Pearson chi-square tests (or equivalent) were performed to examine if there were any differences in the demographic and epilepsy profiles of ESN and Non-ESN site participants, and the care they received. For multi-item scales, total mean scores were calculated and a comparison between ESN and Non-ESN site scores was conducted using independent sample t-tests. The statistical significance level was set at $\mathrm{p}<.05$.

\subsection{Quality and reliability}

The face validity of the survey was established through an iterative collaboration with medical experts and specialists (nurses, psychologists) in the field of epilepsy care to review the survey and provide feedback in relation to its relevance and appropriateness as well as to identify any gaps in the issues examined. Several patient-focused surveys have shown the face validity of the QOLIE instrument items [33], and the shorter version, the QOLIE-10-P 
which was used in this study, was empirically developed from the 89-item QOLIE using psychometrically founded item reduction approaches [34]. Internal reliability analysis of multi-item likert scales was performed using Cronbach's alpha. A high degree of internal reliability was found for the scales used in the study (Table 1). To ensure the quality and accuracy of data entry, prior to data analysis, data were screened, entered, checked and audited. A random sample of 63 questionnaires was selected for audit, representing approximately $12 \%$ of the sample. The error rate was $0.17 \%$ (12 errors from 7,056 data points). Generally, a $5 \%$ error rate is allowed and accounted for in statistical analyses.

\section{Insert Table 1}

\subsection{Ethics}

Ethical approval was granted by the University's Research Ethics Committees and by each participating clinical site. Written study information was given to Directors of Nursing, Medical consultants, ESNs and multidisciplinary team (MDT) members to obtain their support for the study and as part of the recruitment process for their participation in other aspects of the study. Verbal and written study information was given to patients, informing them about the nature of involvement and their right to refuse to participate and withdraw from the study at any time without negative consequences to themselves or the care they received. Consent was assumed by return of the questionnaire. Surveys were confidential and sites were also anonymised using numeric identifiers. All data files were password protected and stored in accordance with the Data Protection (Amendment) Act 2003 [35]. To avoid any potential conflict of interest, clinical staff were not involved in the recruitment of patients for the survey.

\subsection{Sample}

The target sample was 500 returned surveys (250 in ESN sites and 250 in Non-ESN sites). In total 515 surveys were returned, with a total of 505 usable (244 ESN and 261 Non-ESN sites). Across ESN and non ESN sites, the majority of participants were white Irish (approximately 90\%), female (approx. 55\%), living at home (approx. 78\%), educated beyond primary school (approx. 76\%), working or retired from employment (approx 40\%) or in a relationship/married (approx 56\%).

There were no statistically significant differences between Non-ESN and ESN sites in relation to gender, ethnicity, highest educational level, work status, relationship status or living arrangements. There was a statistically significant difference in age groups between the two groups $\left[x^{2}(4)=12.166, p=0.016\right]$, with ESN participants having a younger age profile in comparison to Non-ESN participants. More participants in ESN sites were under 40 compared to those in Non-ESN sites (70.5\% vs. $57.1 \%$ ) (Table 2 ).

\section{Insert Table 2}


The most common types of symptoms experienced during seizures were reported by participants as: loss of awareness (Non-ESN: 71.2\%, ESN: 78.1\%), confusion or agitation (Non-ESN: 69.8\%, ESN: 68.8\%), convulsion (Non-ESN: 59\%, ESN: 61.3\%), staring (Non-ESN: $53.8 \%$, ESN: $63.1 \%$ ), warning or aura (Non-ESN: $51.3 \%$, ESN: $64.4 \%$ ) and falling to the ground (Non-ESN: 56.4\%, ESN: 53.1\%). Statistically significant differences in the symptoms experienced was only found for warning or aura with a higher proportion of people from ESN sites reporting having experienced it $\left[x^{2}(1)=5.555, p=0.018\right]$. There were no statistically significant differences between Non-ESN and ESN sites in terms of their seizures (frequency, duration and recovery) or most of their treatments (on anti-epileptic drugs (AED); have drugs vagal nerve stimulator (VNS); frequency of missed dose). However, a statistically significant higher proportion of participants from ESN sites (12.8\%) reported having had surgery for epilepsy compared to Non-ESN sites $(5.4 \%)\left[x^{2}(1)=8.226, p=0.004\right]$ (Table 3).

\section{Insert Table 3}

\section{Results}

\subsection{Information provided}

Participants attending services with an ESN had statistically significantly higher mean scores in terms of information provided on: the nature of epilepsy [t(470) $=-5.337, p<.001]$; social aspects of epilepsy $[\mathrm{t}(458)=-4.582, \mathrm{p}<0.001]$; safety aspects of epilepsy $[\mathrm{t}(471)=-5.091$, $p<0.001]$ and medical aspects of epilepsy $[t(464)=-3.008, p=.003]$ (Table 4).

\section{Insert Table 4}

While the overall findings support the belief that ESNs make a difference to education on medical aspects of epilepsy, there was little or no difference between ESN and Non-ESN sites in relation to information provided on why specific tests or scans are needed $\left[\mathrm{x}^{2}(4)=\right.$ $3.902, p=.424]$; the results of tests/ scans $\left[x^{2}(4)=1.257, p=.872\right]$; the purpose of antiepileptic medication $\left[\mathrm{x}^{2}(4)=5.191, \mathrm{p}=.275\right]$; how often medications need to be taken [Fisher's exact test $=3.031, \mathrm{p}=.581$ ]; and the implications of not taking anti-epileptic medications $\left[x^{2}(4)=3.013, p=.556\right]$ (Table 5).

\section{Insert Table 5}

\subsection{Involvement in Care}

People with epilepsy were asked to rate four items that addressed the extent to which they were given an opportunity to ask questions, discuss concerns, have their wishes heard and be involved in decision-making around their care and treatment, and one question that asked about family involvement. The ESN sites had higher mean scores for the five items 
compared to Non-ESN sites indicating that ESN participants perceived greater involvement in their care compared to Non-ESN participants. The overall mean score for involvement in care was also higher for ESN sites $(M=4.23, S D=.73)$ compared to Non-ESN sites $(M=3.95$, $\mathrm{SD}=.82)[\mathrm{t}(477)=-4.068, \mathrm{p}<.001]$ (Table 6).

\subsection{Co-ordination of Care}

People with epilepsy were asked to rate four items that addressed co-ordination of care: care delivered in a planned and coordinated manner, easy to make appointments, good follow-up care and reasonable waiting times. Participants from ESN sites had higher mean scores on all four items compared to Non-ESN participants. The total mean score for coordination of care was higher in ESN sites ( $M=3.77$; $S D=.78)$ compared to Non-ESN sites $(\mathrm{M}=3.57 ; \mathrm{SD}=.88)[\mathrm{t}(475)=-2.597, \mathrm{p}=0.01]$ (Table 6).

\section{Insert Table 6}

\subsection{Continuity of care}

A higher proportion of participants in Non-ESN sites strongly agreed/agreed that they meet the same practitioner each time (58.7\%) compared to those in ESN sites (40.6\%) $\left[x^{2}(4)=20.44, p<0.001\right]$. There were no statistically significant differences between Non-ESN sites and ESN sites on their views in relation to whether they had to explain their epilepsy repeatedly to different healthcare professionals $\left[x^{2}(4)=.230, p=0.124\right]$ and whether there was consistency in the information they received $\left[x^{2}(4)=.035, p=0.134\right]$.

\subsection{Confidence in and comfort with care}

Statistically significant differences between ESN sites and Non-ESN sites were found in relation to the two comfort items. No PWE from ESN sites reported not feeling comfortable talking to the ESN compared to 11 PWE from Non-ESN sites who reported discomfort talking to the healthcare professional $\left[x^{2}(2)=10.571, p=0.005\right]$. In relation to talking about sexual issues, a higher proportion of respondents from ESN sites strongly agreed/agreed that they felt comfortable doing so (44.1\%) compared to respondents from Non-ESN sites (35.6\%) $\left[x^{2}(2)=6.692, p=0.035\right]$.

A slightly greater number of PWE from ESN sites strongly agreed/agreed that they had confidence in the ESN to provide the required care (87.9\%) compared to Non-ESN sites $(83.5 \%)\left[x^{2}(2)=9.151, p=0.01\right]$. In relation to trust in advice given, there was a high level of trust in advice given among PWE in the ESN and in Non-ESN sites, with no statistically significant difference emerging between the sites $\left[x^{2}(2)=3.024, p=.220\right]$.

\subsection{Treated with dignity and respect}

There was no statistically significant difference between ESN sites and Non-ESN sites in relation to ESNs/healthcare professionals talking in front of them, with approximately 13- 
$16 \%$ of respondents in both sites reporting that this occurred $\left[x^{2}(4)=.492, p=0.166\right]$. While the majority of participants in both sites agreed that they were treated with dignity and respect (Non-ESN: 90.5\%, ESN: 93.3\%), a statistically significantly higher proportion of participants from ESN sites strongly agreed that they felt they were treated with dignity and respect (58\%) compared to respondents from Non-ESN sites (43\%) [Fisher's exact test $=14.694, p=0.003]$.

\subsection{Satisfaction with emotional and practical support}

People with epilepsy from ESN sites reported higher satisfaction with the practical and emotional support provided $(M=8.05 ; S D=2.13 ; M=7.39, S D=2.47)$ compared to $P W E$ attending Non-ESN sites $(M=7.41 ; S D=2.39 ; M=6.65, S D=2.73)$ and this was statistically significant for both items $[\mathrm{t}(467.022)=-3.080, \mathrm{p}<.002 ; \mathrm{t}(461.315)=-3.056, \mathrm{p}<.002]$.

\subsection{Health and well-being}

There was no difference between ESN sites and non-ESN sites on their views on whether the ESN/healthcare practitioner had a positive impact on their health and well-being, with approximately $80 \%$ of participants from both sites agreeing/strongly agreeing with the statement $\left[x^{2}(2)=5.271, p=0.072\right]$.

\subsection{Quality of Life}

There was huge variation in the QOLIE-10-P scores for the total sample, with a range of 0.28-100. ( $S D=27.53$ ). Three quarters of the total sample scored under 55 , highlighting the low quality of life in this population. There was no statistically significant difference in the mean QOLIE-10-P score between Non-ESN sites $(M=39.15, \quad S D=28.53)$ and $E S N$ sites $(\mathrm{M}=37.34, \mathrm{SD}=26.46)[\mathrm{t}(439)=.690, \mathrm{p}=.491]$.

\section{Discussion}

As far back as 2003, the World Health Organization [36] and, more recently, the Institute of Medicine have highlighted the urgency of addressing unmet needs in people with epilepsy [37]. Many aspects of epilepsy care have been found to be unsatisfactory to PWE, such as the provision of education and information, co-ordination of care and follow-up care $[6,10,11,38,39,40,41]$. While the inclusion of an ESN within the multidisciplinary team will not address all of these systemic challenges, this study, the first study of ESNs in Ireland, clearly indicates that they have the potential to address most of them. This study found that PWE who attended a service with an ESN reported receiving a greater amount of information, being more involved in their care, perceived care to be better coordinated, had greater confidence in the information provided and greater comfort in discussing issues with an ESN. As unmet needs are closely linked to dissatisfaction with care, these findings no doubt contributed to the higher rates of satisfaction with the emotional and practical support offered within the ESN sites. 
Education of patients has been noted as an important function of all clinical specialist and advanced nurse practitioners $[30,42,43,44]$. In the context of chronic disease management and the management of epilepsy, education of PWE is considered critical given the evidence on the lack of knowledge of PWE about their disease and implications for lifestyle $[45,46]$. More educated PWE can better participate in the treatment process, make more informed decisions about investigations and treatments, thus aiding self-management of their condition $[5,47,48,49]$. The findings from this study suggest that ESNs make a difference to some, but not all, aspects of education on the medical aspects of epilepsy, as no difference was found between ESN and Non-ESN sites in relation to information provided on why specific tests or scans are needed; the results of tests/ scans; the purpose of anti-epileptic medication; how often medications need to be taken; and the implications of not taking anti-epileptic medications. These findings are not surprising as, irrespective of whether PWE are attending a site with or without an ESN, they are under the care of a neurologist with expertise in the medical aspects of epilepsy.

While the medical aspects of epilepsy are undoubtedly very important they do not cover the entire spectrum of the condition [12]. Epilepsy is not just a medical diagnosis but is a social label [50], that confers a certain status and identity on the person, and comes with certain psychological and social risks that need to be managed. Thus, providing information on social and safety aspects can provide PWE with the tools to cope better with the emotional and psychological impact of the condition and associated stigma $[47,48]$, educate others about epilepsy and to adapt positively to their condition [47,51], ultimately impacting on their quality of life. Conversely, misinformed and incorrect beliefs among PWE can prolong adjustment and exacerbate feelings of stigma, shame and seizure related anxiety [45], leading to withdrawal from social life and increasing the risk of depression [49]. In this study, the added value of the ESN role appears to be in the contribution they make to the information provided on the social, safety and wider health aspects of epilepsy. There was no evidence that quality of life, as measured by the QOLIE-10-P instrument, or health and well-being, as perceived by participants, were any greater in sites with an ESN. This result may be a reflection of the large variation in QoL scores, suggesting that the choice of tool may not have been the most appropriate. It may also indicate that increases in subjective QoL require major changes in health status, relationships, and social connectedness, before one perceives a significant change in QoL.

In addition to ESNs impacting on information provided, findings indicated that PWE who attended sites with ESNs reported a greater sense of involvement in care in terms of being given the opportunity to ask questions; being given enough time to discuss worries; being involved in decision-making; and having their wishes and needs taken into account. The outcomes on PWE's sense of involvement are important; just as education empowers people to take greater ownership of their care $[47,48]$, studies indicate that people with chronic medical conditions who are involved in their own care and included in decision- 
making feel better equipped to self-manage their condition [17] and report greater satisfaction with care [12]. While the finding in relation to involvement in care may possibly be related to PWE's perception of ESNs' interpersonal and clinical skills, it may also reflect the longer duration of consultations with the ESNs, a finding reported in other studies $[5,6,17]$. There was a high level of trust among PWE in both the ESN and Non-ESN sites in relation to advice given, but a greater proportion of PWE reported comfort in talking to the ESN about their concerns, and confidence in the ESN to provide the care they needed. In particular, comfort in discussing sexual concerns with the ESN was higher, which is an area that has proved difficult for health professionals in other studies [52,53].

Whereas several studies indicate that a lack of time or a perceived lack of time limits PWE's information-seeking behaviour from neurologists and other health professionals $[5,6,7,8,54]$, this study shows that participants in ESN sites experienced greater ease and comfort in addressing concerns, which may be due to ESNs being perceived as more approachable and having more time to answer questions. This greater availability of time among ESNs has also been reported in several qualitative studies, with PWE reporting valuing the time and space ESNs create to talk about their concerns and fears $[5,6,17]$. This greater availability of time and the comfort within consultations perhaps facilitates more information to be exchanged, and may account for the difference between the ESN and non-ESN sites in relation to the provision of information on the social and safety aspects of epilepsy.

Bryant-Lukosius and DiCenso [55] recommend that the primary focus of specialist nurses should be on promoting continuous and coordinated care to improve health outcomes. Given findings of a lack of co-ordinated care, inadequate follow-up care and poor integration between different aspects of services experienced by PWE in Irish studies $[10,11]$, the finding that PWE from ESN sites perceived greater co-ordination in care in terms of care being planned, the ease of making appointments, follow-up care and waiting times being reasonable is heartening. These findings also add to the body of evidence on the reported benefits of ESNs to co-ordination of care $[8,17,18]$. The finding that a higher proportion of PWE attending Non-ESN sites agreed that they meet the same practitioner on each visit is not surprising, as the team in Non-ESN sites consists solely of the medical consultant.

Findings indicate that ESNs have a positive impact in many areas that support the improvement of PWE's knowledge and skills in self-management, their journey through the health care system and satisfaction with the care and support offered. While these mean scores were higher in ESN sites, it is noteworthy that they ranged between 3.5 and 4.5 out of a total of 5 in relation to information provision, indicating that there is still room for improvement. The mean scores were particularly low in providing information on employment and explaining epilepsy to others; two areas where PWE indicate that they 
require significant support and help [56]. Supporting people to disclose is not only important for safety reasons, but has been found to reduce the psychological burden associated with keeping a secret [57] and offset the negative impact that concealment has on self-stigma and social exclusion [58]. In this regard, ESNs could easily support PWE to develop skills and confidence around disclosure by referring them to online resources such as the HOW2TELL app and the booklet hosted on the Epilepsy Ireland website (http://www.epilepsy.ie).

\subsection{Relevance to clinical practice}

To our knowledge, this is the first study evaluating the role of the ESN in Ireland and providing a quantitative measure of the impact of services with an ESN on the care of PWE in comparison to services without an ESN. The findings provide important insights into the added value of having an ESN within the MDT and, in particular, the important role they play in providing detailed person-focused information on epilepsy, as well as facilitating greater involvement of the person in their care and enhancing the co-ordination of care. These findings are strengthened by the fact that satisfaction with the practical support and emotional support offered to PWE was significantly higher in the ESN group. In presenting these findings, the authors have added to the evidence supporting the importance of ESNs in comprehensive health care provision for adults with epilepsy. At the same time we have identified two important areas the ESN needs to give significant attention to, namely employment and disclosure. Given the findings of the study and the limited evidence currently available on the impact of ESN on QoL there is a need for more comprehensive research to explore the effectiveness and impact of ESN roles on the quality of life of PWE.

\subsection{Limitations}

Although the study provides important quantitative findings into the added value of the ESN within a service, there are some methodological limitations that need to be considered when reading the results. The generalisability of the study findings is limited by the convenience nature of the sample, the fact that it is unknown whether the sample obtained was representative of the patient population attending both types of services and our inability to calculate the response/drop out rate. Furthermore, the sample was culturally homogenous with approximately $90 \%$ white Irish, the majority being under the age of 70 years, and well educated (over a third had a third level education). There is also a possibility that those more positively disposed to ESN care completed the survey, or that people were subject to recall bias. Another limitation of this study is that there may have been a heightened risk of making a Type 1 error that is detecting a statistically significant difference when none is present, due to the fact that multiple analyses were conducted. By virtue of the fact that the survey was in English and required people to have literacy skill necessary to self-complete, certain groups of people, such as those who could not speak English or those with literacy or significant learning challenges, were excluded. Thus further research is 
needed to capture these populations, including expanding the ethnic profile and younger and older age groups of participants.

\subsection{Conclusion}

This is the first study in Ireland that explores PWE's perspectives on the impact of the role of the ESN on care provision. The study findings confirmed the efficacy of ESNs in providing patients with advice and counselling them about their epilepsy and epilepsy related care, and providing comparatively better processes of care compared to care in which there was no ESN involvement. Thus, it may be concluded that models of care involving the substantial input of ESNs enhance the quality of epilepsy care and improve satisfaction ratings among PWE. The findings also draw attention to the importance of the ESN-patient relationship and emphasises the need to have an ESN as part of the multidisciplinary team.

\section{Acknowledgements}

This SENsE study was funded by a grant from Epilepsy Ireland and the Health Research Board Ireland (Grant No. MRCG/20125).

\section{Role of the funding source}

The funding source of the study had no role in the study design, data collection, data interpretation, in the writing of the report, or in the decision to submit the article for publication. Epilepsy Ireland, who are part-funders, provided assistance in the advertising and recruitment of sites by sending information letters/emails to Medical Consultants about the study.

\section{Conflicts of interest statement}

There are no known conflicts of interest associated with this publication. 


\section{References}

[1] Engel J, Pedley, T. Epilepsy: a comprehensive textbook. Philadelphia, PA: Lippincott Williams \& Wilkins; 2008.

[2] Higgins A, Elliott N, Varley J, Tyrrell E, Downes C, Begley C, et al. An evaluation of the role of the Epilepsy Specialist Nurse and the impact on patient quality of life: The SENsE study. Dublin: School of Nursing and Midwifery Trinity College Dublin; 2016.

[3] Langfitt J, Wiebe S. Cost-Effectiveness of Epilepsy Therapy: How Should Treatment Effects Be Measured? Epilepsia 2002; 43: 17-24.

[4] Wiebe N, Fiest KM, Dykeman J, Liu X, Jette N, Patten S, et al. Patient satisfaction with care in epilepsy: how much do we know? Epilepsia 2014; 55(3):448-55. doi: 10.1111/epi.12537.

[5] Ridsdale L, Morgan M, O'Connor C. Promoting self-care in epilepsy: the views of patients on the advice they had received from specialists, family doctors and an epilepsy nurse. Patient Education and Counselling 1999a; 37(1): 43-47.

[6] Mills N, Campbell R, Bachmann MO. What do patients want and get from a primary care epilepsy specialist nurse service? Seizure 2002; 11(3): 176-183.

[7] Ridsdale L, Kwan I, Morgan M. How can a nurse intervention help people with newly diagnosed epilepsy? A qualitative study (of patients' views). Seizure 2002; 11(1): 1-5.

[8] Noble AJ, Morgan M, Virdi C, Ridsdale, L. A nurse-led self-management intervention for people who attend emergency departments with epilepsy: the patients' view. Journal of Neurology 2013; 260(4): 1022-1030.

[9] Mahendran M, Speechley KN, Widjaja E. Systematic review of unmet healthcare needs in patients with epilepsy. Epilepsy \& Behavior 2017; 75: 102-109. doi:10.1016/j.yebeh.2017.02.034

[10] Varley J, Delanty N, Normand C, Fitzsimons M. The health care journeys experienced by people with epilepsy in Ireland: What are the implications for future service reform and development? Epilepsy \& Behavior 2011a; 20(2): 299-307.

[11] Varley J, O'Connor R, Delanty N, O'Riordan D, Kenny A, Barry N, et al. Towards the development of integrated epilepsy services: an audit of documented epilepsy care. Irish Medical Journal 2011b; 104(7): 214-217.

[12] Pfäfflin M, Schmitz B, May TW. Efficacy of the epilepsy nurse: Results of a randomized controlled study. Epilepsia 2016; 57: 1190-1198. doi:10.1111/epi.13424

[13] National Institute for Clinical Excellence (NICE). The epilepsies: diagnosis and management of the epilepsies in adults in primary and secondary care. London: NICE; 2004.

[14] National Institute for Clinical Excellence (NICE). Epilepsies: diagnosis and management. Clinical guideline. London: NICE; 2012.

[15] Scrambler A, Scrambler G, Ridsdale L, Robins D. Towards an evaluation of the effectiveness of an epilepsy nurse in primary care. Seizure 1996; 5: 225-228. 
[16] Sarkissian S, Wennberg R. Effects of the acute care nurse practitioner role on epilepsy monitoring outcomes. Outcomes Management for Nursing Practice 1999; 3(4): 161-166.

[17] Kirton JA, Jack BA, O'Brien MR, Roe B. Care of patients with neurological conditions: the impact of a Generic Neurology Nursing Service development on patients and their carers. Journal of Clinical Nursing 2012; 21(1-2): 207-215.

[18] Taylor MP, Readman S, Hague B, Boulter V, Hughes L, Howell S. A district epilepsy service, with community-based specialist liaison nurses and guidelines for shared care. Seizure 1994; 3(2): 121-127.

[19] Ridsdale L, Robins D, Cryer C, Williams H. Feasibility and effects of nurse run clinics for patients with epilepsy in general practice: randomised controlled trial. Epilepsy Care Evaluation Group. British Medical Journal 1997; 314(7074): 120-122.

[20] Meads C, Burls A, Bradley P. Systematic reviews of specialist epilepsy services. Seizure 2002; 11(2): 90-98.

[21] Bradley PM, Lindsay B, Fleeman N. Care delivery and self management strategies for adults with epilepsy. Cochrane Database Systematic Reviews 2016; 2, CD006244.

[22] Health Service Executive (HSE). The National Clinical Programme in Epilepsy Care in Ireland. Dublin: HSE; 2014.

[23] National Council for the Professional Development of Nursing and Midwifery (NCNM). Framework for the Establishment of Clinical Nurse/ Midwife Specialist Posts. Dublin: NCNM; 2008a.

[24] National Council for the Professional Development of Nursing and Midwifery (NCNM). Framework for the Establishment of Advanced Nurse Practitioner and Advanced Midwife Practitioner Posts. Dublin: NCNM; 2008b.

[25] Parahoo K. Nursing Research: Principles, Process and Issues. 2nd ed. Houndsmill: Palgrave Macmillan; 2006.

[26] de Vaus D. Surveys in Social Research. 6th ed. London: Routledge; 2014.

[27] Begley C, Murphy K, Higgins A, Elliott N, Lalor J, Sheerin F, et al. Evaluation of Clinical Nurse and Midwife Specialist and Advanced Nurse and Midwife Practitioner Roles in Ireland (SCAPE): Final Report. Dublin: National Council for the Professional Development of Nursing and Midwifery in Ireland; 2010.

[28] Begley C, Elliott N, Lalor J, Coyne I, Higgins A, Comiskey CM. Differences between clinical specialist and advanced practitioner clinical practice, leadership, and research roles, responsibilities, and perceived outcomes (the SCAPE study). Journal of Advanced Nursing 2013; 69(6): 1323-1337.

[29] Comiskey C, Coyne I, Lalor J, Begley C. A national cross sectional study measuring predictors for improved service user outcomes across clinical nurse or midwife specialist, advanced nurse practitioner and control sites in Ireland. Journal of Advanced Nursing 2014; 70(5): 1128-37.

[30] Coyne I, Comiskey C, Lalor J, Higgins A, Elliott N, Begley C. An exploration of clinical practice in sites with and without clinical nurse or midwife specialists or advanced 
nurse practitioners, in Ireland. BMC Health Services Research 2016; 16: 151. doi:

10.1186/s12913-016-1412-8.

[31] Cramer JA, Perrine K, Devinsky O, Meador K. A brief questionnaire to screen for quality of life in epilepsy: the QOLIE-10. Epilepsia 1996; 37(6): 577-582.

[32] IBM Corp. IBM SPSS Statistics for Windows, Version 21.0. Armonk, NY: IBM Corp; Released 2012.

[33] Cramer JA, Van Hamme G, the N132 Study Group. Maintenance of improvement of health-related quality of life during long-term treatment with levetiracetam. Epilepsy Behavior 2003; 4: 118-23.

[34] Pfäfflin M, Fraser RT, Thorbecke R, Specht U, Wolf P. Comprehensive care for people with epilepsy. Eastleigh: John Libbey; 2001.

[35] Data Protection (Amendment) Act 2003, Public Act no. 6 of 2003, Act of the Irish parliament.

[36] World Health Organization (WHO), International League Against Epilepsy (ILAE), professionals International Bureau for Epilepsy, lay persons Global campaign against epilepsy (IBE).

http://www.who.int/mental health/management/en/GcaeBroEn.pdf?ua=1; 2003 [accessed 13 March 2018].

[37] England MJ, Liverman CT, Schultz AM, Strawbridge LM. Epilepsy Across the Spectrum: Promoting Health and Understanding. Washington (DC): National Academies Press; 2012.

[38] Ridsdale L. Matching the needs with skills in epilepsy care. British Medical Journal 1995; 310(6989): 1219.

[39] Thapar AK. Care of patients with epilepsy in the community: will new initiatives address old problems? British Journal of General Practice 1996; 46(402): 37-42.

[40] Ridsdale L, Robins D, Fitzgerald A, Jeffery S, McGee L. Epilepsy monitoring and advice recorded: general practitioners' views, current practice and patients' preferences. British Journal of General Practice 1996; 46(402): 11-14.

[41] Ridsdale L. Kwan I, Cryer C. Newly diagnosed epilepsy: can nurse specialists help? A randomized controlled trial. Epilepsy Care Evaluation Group. Epilepsia 2000; 41(8): 1014-1019.

[42] National Council for the Professional Development of Nursing and Midwifery (NCNM). An Evaluation of the Effectiveness of the Role of the Clinical Nurse/Midwife Specialist. Dublin: NCNM; 2004.

[43] National Council for the Professional Development of Nursing and Midwifery (NCNM). A Preliminary Evaluation of the Role of the Advanced Nurse Practitioner. Dublin: NCNM; 2005.

[44] Gerrish K, Ashworth P, Lacey A, Bailey J, Cooke J, Kendall S, et al. Factors influencing the development of evidence-based practice: a research tool. Journal of Advanced Nursing 2007; 57(3): 328-338. 
[45] Mameniskiene R, Sakalauskaite-Juodeikiene E, Budrys V. People with epilepsy lack knowledge about their disease. Epilepsy Behav 2015; 46: 192-7.

[46] Suresh D, Aggarwal M, Srivastava A, Singh MB. A Comparative Study to Assess the Knowledge of Caregivers of People with Epilepsy and General Public Regarding Epilepsy and its First- Aid Management. Asian Journal of Nursing Education and Research, 2017; 7(2): 147-150.

[47] Helde G, Brodtkorb E, Brathen G, Bovim G. An easily performed group education programme for patients with uncontrolled epilepsy-a pilot study. Seizure 2003; 12(7): 497-501.

[48] Doughty J, Baker GA, Jacoby A, Lavaud V. Cross-cultural differences in levels of knowledge about epilepsy. Epilepsia 2003; 44(1): 115-123.

[49] May TW, Pfäfflin M. Psychoeducational Programs for Patients with Epilepsy. Disease Management \& Health Outcomes 2005; 13(3): 185-199.

[50] Räty LK, Wilde-Larsson BM. Patients' perceptions of living with epilepsy: a phenomenographic study.J Clin Nurs 2011; 20(13-14): 1993-2002. doi: 10.1111/j.1365-2702.2010.03572.x.

[51] Couldridge L, Kendall S, March A. A systematic overview-a decade of research'. The information and counselling needs of people with epilepsy. Seizure 2001; 10(8): 605614.

[52] Higgins A, Barker P, Begley C. 'Veiling sexualities': a grounded theory of mental health nurses' responses to issues of sexuality. Journal of Advanced Nursing 2008; 62(3): 307-317.

[53] Higgins A, Barker P, Begley C. Sexuality and mental health nursing in Ireland: weaving the veil of socialised inhibition. Nurse Education Today 2009; 29: 357-364.

[54] Ridsdale L, Kwan I, Cryer C. The effect of a special nurse on patients' knowledge of epilepsy and their emotional state. Epilepsy Evaluation Care Group. The British Journal of General Practice 1999b; 49(441): 285-289.

[55] Bryant-Lukosius D, DiCenso A. A framework for the introduction and evaluation of advanced practice nursing roles. Journal of Advanced Nursing 2004; 48: 530-540. doi:10.1111/j.1365-2648.2004.03235.x

[56] Epilepsy Ireland.

http://www.epilepsy.ie/index.cfm/spKey/seizureaware.surveyresults.html; 2012 [accessed 13 March 2018]

[57] Pembroke S, Higgins A, Pender N, Elliott N. Becoming comfortable with "my" epilepsy: Strategies that patients use in the journey from diagnosis to acceptance and disclosure. Epilepsy \& Behavior 2017; 70: 217-223.

[58] Yennadiou $\mathrm{H}$, Wolverson E. The experience of epilepsy in later life: A qualitative exploration of illness representations. Epilepsy Behav 2017; 70: 87-93. doi: 10.1016/j.yebeh.2017.01.033. 
Table 1: Internal reliability analysis

\begin{tabular}{lc}
\hline Measure & $\begin{array}{c}\text { Cronbach's } \\
\text { Alpha }\end{array}$ \\
\hline Information provided on the nature of epilepsy and own epilepsy (4 items) & 0.777 \\
Information provided on medical aspects of epilepsy (9 items) & 0.890 \\
Information provided on social aspects of epilepsy (3 items) & 0.836 \\
Information provided on safety aspects of epilepsy (4 items) & 0.824 \\
Involvement in care (5 items) & 0.891 \\
Co-ordination of care (4 items) & 0.727 \\
\hline
\end{tabular}


Table 2: Demographic profile of participants

\begin{tabular}{|c|c|c|c|c|c|c|}
\hline & & \multicolumn{2}{|c|}{ Non-ESN } & \multicolumn{2}{|c|}{ ESN } & \multirow[t]{2}{*}{$\mathrm{X}^{2}$} \\
\hline & & $\mathbf{n}$ & $\%$ & $\mathbf{n}$ & $\%$ & \\
\hline \multirow[t]{2}{*}{ Gender } & Male & 116 & $45.1 \%$ & 105 & $43.2 \%$ & $x^{2}(1)=.188$ \\
\hline & Female & 141 & $54.9 \%$ & 138 & $56.8 \%$ & $p=.366^{\mathrm{ns}}$ \\
\hline \multirow[t]{5}{*}{ Age } & $18-20$ & 23 & $9.2 \%$ & 17 & $7.2 \%$ & $x^{2}(4)=12.166$, \\
\hline & $21-30$ & 57 & $22.8 \%$ & 69 & $29.1 \%$ & $p=0.016^{* *}$ \\
\hline & $31-40$ & 63 & $25.2 \%$ & 81 & $34.2 \%$ & \\
\hline & $41-50$ & 47 & $18.8 \%$ & 27 & $11.4 \%$ & \\
\hline & $51+$ & 60 & $24 \%$ & 43 & $18.1 \%$ & \\
\hline Relationship & Single & 84 & $35 \%$ & 93 & $39.9 \%$ & $x^{2}(4)=3.89$ \\
\hline \multirow[t]{4}{*}{ Status } & In a relationship & 56 & $22.8 \%$ & 59 & $25.3 \%$ & $\mathrm{p}=.421^{\mathrm{ns}}$ \\
\hline & Married/Civil Partnership & 89 & $36.2 \%$ & 70 & $30 \%$ & \\
\hline & Separated/ Divorced & 13 & $5.3 \%$ & 7 & $3 \%$ & \\
\hline & Widowed & 3 & $1.2 \%$ & 4 & $1.7 \%$ & \\
\hline Living & Live alone & 30 & $12.6 \%$ & 21 & $9.1 \%$ & $x^{2}(4)=6.020$ \\
\hline \multirow[t]{4}{*}{ Arrangements } & Live with family & 185 & $77.4 \%$ & 179 & $77.5 \%$ & $\mathrm{p}=.198^{\mathrm{ns}}$ \\
\hline & Live with flatmates/ friends & 8 & $3.3 \%$ & 17 & $7.4 \%$ & \\
\hline & Supported accomm/Residential Care & 3 & $1.3 \%$ & 5 & $2.2 \%$ & \\
\hline & Other & 13 & $5.4 \%$ & 9 & $3.9 \%$ & \\
\hline \multirow[t]{3}{*}{ Ethnicity } & White Irish & 214 & $89.5 \%$ & 215 & $92.3 \%$ & $x^{2}(2)=2.741$ \\
\hline & White Irish Traveller/White Non Irish & 22 & $9.2 \%$ & 13 & $5.6 \%$ & $p=.254^{\mathrm{ns}}$ \\
\hline & Other $^{+}$ & 3 & $1.3 \%$ & 5 & $2.1 \%$ & \\
\hline Highest Level & No Formal Education & 3 & $1.2 \%$ & 3 & $1.3 \%$ & $x^{2}(4)=5.803$ \\
\hline \multirow[t]{4}{*}{ of Education } & Primary & 29 & $11.9 \%$ & 16 & $6.9 \%$ & $\mathrm{p}=.214^{\mathrm{ns}}$ \\
\hline & Secondary & 103 & $42.4 \%$ & 92 & $39.7 \%$ & \\
\hline & Technical/Vocational & 21 & $8.6 \%$ & 30 & $12.9 \%$ & \\
\hline & Third Level & 87 & $35.8 \%$ & 91 & $39.2 \%$ & \\
\hline Current Work & Working for payment or profit & 81 & $33.6 \%$ & 82 & $35.5 \%$ & $x^{2}(6)=3.901$ \\
\hline \multirow[t]{6}{*}{ Status } & Unemployed looking for work & 26 & $10.8 \%$ & 37 & $16 \%$ & $\mathrm{p}=.690^{\mathrm{ns}}$ \\
\hline & Student or pupil & 24 & $10 \%$ & 20 & $8.7 \%$ & \\
\hline & Looking after home or family & 22 & $9.1 \%$ & 20 & $8.7 \%$ & \\
\hline & Retired from employment & 17 & $7.1 \%$ & 13 & $5.6 \%$ & \\
\hline & Unable to work & 58 & $24.1 \%$ & 47 & $20.3 \%$ & \\
\hline & Other & 13 & $5.4 \%$ & 12 & $5.2 \%$ & \\
\hline
\end{tabular}

+Other ethnicity: Including Black/Black Irish, Asian/Asian Irish and Mixed ns not significant ${ }^{* *}$ significant at $p<0.01$ 
Table 3: Epilepsy profile of participants

\begin{tabular}{|c|c|c|c|c|c|c|}
\hline & & & -ESN & & $\mathbf{N}$ & $\mathrm{X}^{2}$ \\
\hline & & $\mathbf{n}$ & $\%$ & $\mathbf{n}$ & $\%$ & \\
\hline Length of time of having & Less Than A Month & 3 & $1.2 \%$ & 1 & $.4 \%$ & $\mathrm{x}^{2}(4)=.966$ \\
\hline epilepsy & Less Than A Year & 7 & $2.7 \%$ & 7 & $2.9 \%$ & $p=.915^{\text {ns }}$ \\
\hline & 1-2 Years & 21 & $8.2 \%$ & 19 & $7.8 \%$ & \\
\hline & 3-4 Years & 27 & $10.5 \%$ & 27 & $11.1 \%$ & \\
\hline & $5+$ Years & 199 & $77.4 \%$ & 189 & $77.8 \%$ & \\
\hline Currently taking anti- & Yes & 250 & $96.2 \%$ & 238 & $98.8 \%$ & $x^{2}(1)=3.349$, \\
\hline epileptic drugs (AEDs) & No & 10 & $3.8 \%$ & 3 & $1.2 \%$ & $p=0.67^{n s}$ \\
\hline Frequency of missed & Once a week & 13 & $5.3 \%$ & 13 & $5.6 \%$ & $x^{2}(3)=.763$ \\
\hline dose & Few times a month & 23 & $9.4 \%$ & 17 & $7.3 \%$ & $p=0.858^{n s}$ \\
\hline & Few times a year & 34 & $13.9 \%$ & 31 & $13.4 \%$ & \\
\hline & Rarely/ Never & 174 & $71.3 \%$ & 171 & $73.7 \%$ & \\
\hline Have vagal nerve & Yes & 11 & $4.5 \%$ & 15 & $6.5 \%$ & $\mathrm{x}^{2}(1)=.989$ \\
\hline stimulator (VNS) & No & 236 & $95.5 \%$ & 215 & $93.5 \%$ & $p=0.32^{\mathrm{ns}}$ \\
\hline Have had surgery for & Yes & 14 & $5.4 \%$ & 31 & $12.8 \%$ & $x^{2}(1)=8.226$, \\
\hline epilepsy & No & 244 & $94.6 \%$ & 212 & $87.2 \%$ & $p=0.004^{* *}$ \\
\hline Frequency of seizures & Daily & 7 & $2.7 \%$ & 13 & $5.5 \%$ & $x^{2}(5)=4.282$, \\
\hline & Few Times a Week & 18 & $7.1 \%$ & 18 & $7.6 \%$ & $p=0.510^{\text {ns }}$ \\
\hline & Few Times a Month & 42 & $16.5 \%$ & 41 & $17.2 \%$ & \\
\hline & Few Times a Year & 56 & $22 \%$ & 49 & $20.6 \%$ & \\
\hline & Seizure Free & 106 & $39.2 \%$ & 80 & $33.6 \%$ & \\
\hline & Other & 32 & $12.5 \%$ & 37 & $15.5 \%$ & \\
\hline Duration of seizures & Less than 10 seconds & 10 & $7.2 \%$ & 17 & $11.6 \%$ & $x^{2}(4)=6.573$, \\
\hline & $10-59$ seconds & 40 & $28.8 \%$ & 45 & $30.6 \%$ & $p=0.160^{\text {ns }}$ \\
\hline & $1-10$ minutes & 70 & $50.4 \%$ & 74 & $50.3 \%$ & \\
\hline & $11-30$ minutes & 8 & $5.8 \%$ & 8 & $5.4 \%$ & \\
\hline & $>30$ minutes & 11 & $7.9 \%$ & 3 & $2 \%$ & \\
\hline Recovery time after a & Less than 1 minute & 24 & $15.4 \%$ & 23 & $14.5 \%$ & $x^{2}(5)=2.889$, \\
\hline seizure & $1-10$ minutes & 38 & $24.4 \%$ & 36 & $22.6 \%$ & $\mathrm{p}=0.717^{\mathrm{ns}}$ \\
\hline & $11-30$ minutes & 19 & $12.2 \%$ & 30 & $18.9 \%$ & \\
\hline & $31-59$ minutes & 14 & $9 \%$ & 15 & $9.4 \%$ & \\
\hline & $1-3$ hours & 29 & $18.6 \%$ & 27 & $17 \%$ & \\
\hline & More than 3 hours & 32 & $20.5 \%$ & 28 & $17.6 \%$ & \\
\hline
\end{tabular}

ns not significant ${ }^{* *}$ significant at $p<0.01$ 


\begin{tabular}{|c|c|c|c|c|c|c|}
\hline \multirow[t]{2}{*}{ Types of Symptoms } & & \multicolumn{2}{|c|}{ Non-ESN } & \multicolumn{2}{|c|}{ ESN } & \multirow[t]{2}{*}{$\mathrm{X}^{2}$} \\
\hline & & $\mathbf{n}$ & $\%$ & $\mathbf{n}$ & $\%$ & \\
\hline \multirow[t]{2}{*}{ Loss of awareness } & Yes & 111 & $71.2 \%$ & 125 & $78.1 \%$ & \multirow{2}{*}{$\begin{array}{c}x^{2}(1)=2.030, \\
p=0.154^{\text {ns }}\end{array}$} \\
\hline & No & 45 & $28.8 \%$ & 35 & $21.9 \%$ & \\
\hline \multirow[t]{2}{*}{ Warning or Aura } & Yes & 80 & $51.3 \%$ & 103 & $64.4 \%$ & \multirow{2}{*}{$\begin{array}{c}x^{2}(1)=5.555, \\
p=0.018^{*}\end{array}$} \\
\hline & No & 76 & $48.7 \%$ & 57 & $35.6 \%$ & \\
\hline \multirow[t]{2}{*}{ Drop/Spill Object } & Yes & 60 & $38.5 \%$ & 56 & $35 \%$ & \multirow{2}{*}{$\begin{array}{c}x^{2}(1)=.407 \\
p=0.523^{n s}\end{array}$} \\
\hline & No & 96 & $61.5 \%$ & 104 & $65 \%$ & \\
\hline \multirow[t]{2}{*}{ Fall to Ground } & Yes & 88 & $56.4 \%$ & 85 & $53.1 \%$ & \multirow{2}{*}{$\begin{array}{c}x^{2}(1)=.557 \\
p=0.344^{n s}\end{array}$} \\
\hline & No & 68 & $43.3 \%$ & 75 & $46.9 \%$ & \\
\hline \multirow[t]{2}{*}{ Injury } & Yes & 70 & $44.9 \%$ & 68 & $42.5 \%$ & \multirow{2}{*}{$\begin{array}{c}x^{2}(1)=.181 \\
p=0.671^{\text {ns }}\end{array}$} \\
\hline & No & 86 & $55.1 \%$ & 92 & $57.5 \%$ & \\
\hline \multirow[t]{2}{*}{ Tongue Biting } & Yes & 65 & $41.7 \%$ & 75 & $46.9 \%$ & \multirow{2}{*}{$\begin{array}{c}\mathrm{x}^{2}(1)=.868 \\
\mathrm{p}=0.351^{\mathrm{ns}}\end{array}$} \\
\hline & No & 91 & $58.3 \%$ & 85 & $53.1 \%$ & \\
\hline \multirow[t]{2}{*}{ Incontinent } & Yes & 45 & $28.8 \%$ & 39 & $24.4 \%$ & \multirow{2}{*}{$\begin{array}{c}x^{2}(1)=.809 \\
p=0.368^{n s}\end{array}$} \\
\hline & No & 111 & $71.2 \%$ & 121 & $75.6 \%$ & \\
\hline \multirow[t]{2}{*}{ Automatism } & Yes & 65 & $41.7 \%$ & 58 & $36.3 \%$ & \multirow{2}{*}{$\begin{array}{c}x^{2}(1)=.975 \\
p=0.323^{n s}\end{array}$} \\
\hline & No & 91 & $58.3 \%$ & 102 & $63.8 \%$ & \\
\hline \multirow[t]{2}{*}{ Convulsion } & Yes & 92 & $59 \%$ & 98 & $61.3 \%$ & \multirow{2}{*}{$\begin{array}{c}x^{2}(1)=.171 \\
p=0.680^{n s}\end{array}$} \\
\hline & No & 64 & $41 \%$ & 62 & $38.8 \%$ & \\
\hline \multirow[t]{2}{*}{ Staring } & Yes & 84 & $53.8 \%$ & 101 & $63.1 \%$ & \multirow{2}{*}{$\begin{array}{c}x^{2}(1)=2.802 \\
p=0.094^{n s}\end{array}$} \\
\hline & No & 72 & $46.2 \%$ & 59 & $36.9 \%$ & \\
\hline \multirow[t]{2}{*}{ Confusion/Agitation } & Yes & 109 & $69.8 \%$ & 110 & $68.8 \%$ & \multirow{2}{*}{$\begin{array}{c}x^{2}(1)=0.047 \\
p=0.829^{n s}\end{array}$} \\
\hline & No & 47 & $30.1 \%$ & 50 & $31.3 \%$ & \\
\hline
\end{tabular}

ns not significant ${ }^{*}$ significant at $p<0.05$ 
Table 4: Information provided on epilepsy by ESN/healthcare professional (mean scores)

\begin{tabular}{lcc}
\hline Provided information on.... & $\begin{array}{c}\text { Non-ESN } \\
\text { Mean (SD) }\end{array}$ & $\begin{array}{c}\text { ESN } \\
\text { Mean (SD) }\end{array}$ \\
\hline The nature of epilepsy and own epilepsy & & \\
What epilepsy is & $4.01(.99)$ & $4.29(.83)$ \\
What type of epilepsy I have & $3.73(1.07)$ & $4.03(1.02)$ \\
How to keep a seizure diary & $3.25(1.24)$ & $3.83(1.08)$ \\
How to keep myself healthy and well & $3.56(1.15)$ & $4.02(1.01)$ \\
Total mean score & $3.65(0.84)$ & $4.06(0.80)$ \\
Medical aspects of epilepsy & & \\
Why I need specific tests, assessments, or scans & $3.91(1.04)$ & $4.01(1.00)$ \\
The results of my tests, assessments, or scans & $3.87(1.02)$ & $3.94(1.01)$ \\
The purpose of my anti-epileptic medications & $4.19(.89)$ & $4.25(.75)$ \\
How often I need to take my anti-epileptic medications & $4.42(.71)$ & $4.41(.75)$ \\
The implications of not taking my anti-epileptic medications & $4.14(.93)$ & $4.23(.88)$ \\
How my anti-epileptic meds might interact with alcohol and other meds & $3.81(1.07)$ & $4.12(.91)$ \\
How to recognise the side-effects of my anti-epileptic medications & $3.38(1.19)$ & $3.67(1.09)$ \\
What to do if I experience side-effects & $3.27(1.24)$ & $3.73(1.04)$ \\
The procedures for changing anti-epileptic medications & $3.68(1.17)$ & $3.88(1.08)$ \\
Total mean score & $3.85(0.74)$ & $4.05(0.72)$ \\
Social aspects of epilepsy & & \\
How to explain about my epilepsy to others & $3.13(1.25)$ & $3.52(1.18)$ \\
What I need to know about epilepsy and employment & $3.06(1.23)$ & $3.38(1.22)$ \\
Epilepsy organisations and services & $3.24(1.21)$ & $3.78(1.03)$ \\
Total mean score & $3.16(1.07)$ & $3.60(1.02)$ \\
Safety aspects of epilepsy & & \\
How to maintain my own safety and prevent injury & $3.42(1.19)$ & $3.83(1.11)$ \\
What to do in case of an emergency & $3.52(1.18)$ & $4.03(1.03)$ \\
What I need to know about epilepsy and driving & $3.88(1.06)$ & $4.08(0.97)$ \\
Who to contact if seizures continue & $3.72(1.14)$ & $4.22(0.84)$ \\
Total mean score & $3.65(0.93)$ & $4.06(0.81)$ \\
Pregnancy related information & & \\
Advice on anti-epileptic medications and pregnancy & $3.52(1.30)$ & $3.92(1.20)$ \\
\hline & & \\
\hline
\end{tabular}


Table 5: Information provided on epilepsy by ESN/healthcare professional

\begin{tabular}{|c|c|c|c|c|c|c|c|}
\hline Information provided on.... & & $\begin{array}{c}\text { Strongly } \\
\text { Disagree } \\
\%(n) \\
\end{array}$ & $\begin{array}{c}\text { Disagree } \\
\%(n)\end{array}$ & $\begin{array}{c}\text { Neither } \\
\%(n)\end{array}$ & $\begin{array}{l}\text { Agree } \\
\%(n)\end{array}$ & $\begin{array}{c}\text { Strongly } \\
\text { Agree } \\
\%(n) \\
\end{array}$ & $\mathrm{X}^{2}$ test \\
\hline \multicolumn{8}{|l|}{ Nature of epilepsy and own epilepsy } \\
\hline \multirow[t]{2}{*}{ What epilepsy is } & Non-ESN (240) & $2.5(6)$ & $5.8(14)$ & $15.4(37)$ & $40.8(98)$ & $35.4(85)$ & $10.869(4), p=0.025^{*}$ \\
\hline & ESN (210) & $0.5(1)$ & $3.3(7)$ & $11(23)$ & $37.1(78)$ & $48.1(101)$ & \\
\hline \multirow[t]{2}{*}{ What type of epilepsy I have } & Non-ESN (237) & $3.8(9)$ & $10.5(25)$ & $19.8(47)$ & $40.1(95)$ & $25.7(61)$ & $11.452(4), p=0.021^{*}$ \\
\hline & ESN (209) & $1.9(4)$ & $7.7(16)$ & $15.8(33)$ & $34.4(72)$ & $40.2(84)$ & \\
\hline \multirow[t]{2}{*}{ How to keep a seizure diary } & Non-ESN (235) & $9.8(23)$ & $18.7(44)$ & $28.1(66)$ & $23.8(56)$ & $19.6(46)$ & $31.370(4), p=0.000^{* * *}$ \\
\hline & ESN (210) & $3.8(8)$ & $5.2(11)$ & $29(61)$ & $28.1(59)$ & $33.8(71)$ & \\
\hline \multirow[t]{2}{*}{ How to keep myself healthy and well } & Non-ESN (240) & $5.0(11)$ & $15.8(38)$ & $20.0(48)$ & $36.7(88)$ & $22.5(54)$ & $20.799(4), p=0.000^{* * *}$ \\
\hline & ESN (216) & $1.4(3)$ & $7.9(17)$ & $16.7(36)$ & $35.6(77)$ & $38.4(83)$ & \\
\hline \multicolumn{8}{|l|}{ Medical aspects of epilepsy } \\
\hline \multirow[t]{2}{*}{ Why I need specific tests/assessments/scans } & Non-ESN (238) & $2.5(6)$ & $9.2(22)$ & $16.0(38)$ & $39.5(94)$ & $32.8(78)$ & $3.902(4), p=.424^{n s}$ \\
\hline & ESN (212) & $1.4(3)$ & $7.1(15)$ & $18.9(40)$ & $34(72)$ & $38.7(82)$ & \\
\hline \multirow[t]{2}{*}{ The results of my tests/assessments/scans } & Non-ESN (238) & $2.6(6)$ & $8.6(20)$ & $18(42)$ & $40.8(95)$ & $30.0(70)$ & $1.257(4), p=.872^{n s}$ \\
\hline & ESN (208) & $2.4(5)$ & $6.7(14)$ & $19.2(40)$ & $38(79)$ & $33.7(70)$ & \\
\hline \multirow[t]{2}{*}{ The purpose of my AEDs } & Non-ESN (241) & $1.7(4)$ & $4.1(10)$ & $9.5(23)$ & $43.2(104)$ & $41.5(100)$ & $5.191(4), p=.275^{\mathrm{ns}}$ \\
\hline & $\operatorname{ESN}(211)$ & 0 & $2.4(5)$ & $11.8(25)$ & $44.5(94)$ & $41.2(87)$ & \\
\hline \multirow[t]{2}{*}{ How often I need to take my medications? } & Non-ESN (237) & $0.8(2)$ & $0.8(2)$ & $5(12)$ & $41.8(99)$ & $51.5(122)$ & Fisher's exact test: \\
\hline & ESN (215) & $0.5(1)$ & $1.9(4)$ & $7.4(16)$ & $36.7(79)$ & $53.5(115)$ & $3.031, p=.581^{n s}$ \\
\hline \multirow[t]{2}{*}{ The implications of not taking my AEDs } & Non-ESN (228) & $0.4(1)$ & $7.0(16)$ & $13.2(30)$ & $37.3(85)$ & $42.1(96)$ & $3.013(4), p=.556^{n s}$ \\
\hline & ESN (208) & $1.0(2)$ & $3.8(8)$ & $13(27)$ & $35.6(74)$ & $46.6(97)$ & \\
\hline \multirow[t]{2}{*}{ How my AEDs might interact with alcohol. } & Non-ESN (240) & $2.1(5)$ & $12.1(29)$ & $19.2(46)$ & $35.8(86)$ & $30.8(74)$ & $11.744(4), p=0.019^{*}$ \\
\hline & ESN (210) & $0.5(1)$ & $5.2(11)$ & $17.6(37)$ & $35.2(74)$ & $41.4(87)$ & \\
\hline How to recognise the side-effects of my AEDs & Non-ESN (239) & $3.8(9)$ & $25.1(60)$ & $23.4(56)$ & $25.1(60)$ & $22.6(54)$ & $15.272(4), p=.004^{* *}$ \\
\hline
\end{tabular}




\begin{tabular}{|c|c|c|c|c|c|c|c|}
\hline & ESN (211) & $2.8(6)$ & $11.4(24)$ & $30.3(64)$ & $27(57)$ & $28.4(60)$ & \\
\hline \multirow[t]{2}{*}{ What to do if I experience side-effects } & Non-ESN (236) & $6.8(16)$ & $26.3(62)$ & $20.8(49)$ & $25.8(61)$ & $20.3(48)$ & $33.695(4), p=0.000^{* * *}$ \\
\hline & ESN (208) & $2.4(5)$ & $8.2(17)$ & $32.2(67)$ & $28.8(60)$ & $28.4(59)$ & \\
\hline \multirow[t]{2}{*}{ The procedures for changing AEDs } & Non-ESN (239) & $4.2(10)$ & $15.1(36)$ & $19.2(46)$ & $31.8(76)$ & $29.7(71)$ & $10.033(4), p=0.040^{*}$ \\
\hline & ESN (209) & $3.3(7)$ & $6.7(14)$ & $24.4(51)$ & $29.7(62)$ & $35.9(75)$ & \\
\hline \multicolumn{8}{|l|}{ Social aspects of epilepsy } \\
\hline \multirow[t]{2}{*}{ How to explain my epilepsy to others } & Non-ESN (235) & $11.1(26)$ & $21.7(51)$ & $27.7(65)$ & $22.6(53)$ & $17.0(40)$ & $11.625(4), p=0.020^{*}$ \\
\hline & $\operatorname{ESN}(205)$ & $4.9(10)$ & $16.1(33)$ & $27.8(57)$ & $24.9(51)$ & $26.3(54)$ & \\
\hline \multirow{2}{*}{$\begin{array}{l}\text { What I need to know about epilepsy and } \\
\text { employment }\end{array}$} & Non-ESN (237) & $10.5(25)$ & $24.5(58)$ & $29.1(69)$ & $19.8(47)$ & $16.0(38)$ & $7.859(4), p=0.097^{n s}$ \\
\hline & ESN (209) & $6.2(13)$ & $19.1(40)$ & $29.2(61)$ & $21.1(44)$ & $24.4(51)$ & \\
\hline \multirow[t]{2}{*}{ Epilepsy organisations and services } & Non-ESN (235) & $8.1(19)$ & $21.7(51)$ & $25.5(60)$ & $27.2(64)$ & $17.4(41)$ & $29.531(4), p=0.000^{* * *}$ \\
\hline & $\operatorname{ESN}(212)$ & $1.9(4)$ & $8.5(18)$ & $29.2(62)$ & $30.2(64)$ & $30.2(64)$ & \\
\hline \multicolumn{8}{|l|}{ Safety aspects of epilepsy } \\
\hline \multirow[t]{2}{*}{ How to maintain own safety and prevent injury } & Non-ESN (236) & $5.9(14)$ & $19.5(46)$ & $22.9(54)$ & $30.5(72)$ & $21.2(50)$ & $14.578(4), p=0.006^{* *}$ \\
\hline & ESN (208) & $3.4(7)$ & $10.6(22)$ & $19.2(40)$ & $33.2(69)$ & $33.7(70)$ & \\
\hline \multirow[t]{2}{*}{ What to do in case of an emergency } & Non-ESN (241) & $5.5(13)$ & $16.9(40)$ & $21.2(50)$ & $33.1(78)$ & $23.3(55)$ & $25.117(4), p=0.000^{* * *}$ \\
\hline & $\operatorname{ESN}(214)$ & $2.8(6)$ & $5.6(12)$ & $17.3(37)$ & $34.6(74)$ & $39.7(85)$ & \\
\hline \multirow[t]{2}{*}{ Epilepsy and driving } & Non-ESN (234) & $3.4(8)$ & $9.8(23)$ & $13.2(31)$ & $42.7(100)$ & $30.8(72)$ & $12.467(4), p=0.014^{*}$ \\
\hline & ESN (219) & $0.5(1)$ & $8.2(18)$ & $16(35)$ & $33.3(73)$ & $42(92)$ & \\
\hline \multirow[t]{2}{*}{ Who to contact if seizures continue } & Non-ESN (238) & $4.6(11)$ & $13(31)$ & $15.5(37)$ & $39.5(94)$ & $27.3(65)$ & $30.406(4), p=0.000^{* * *}$ \\
\hline & $\operatorname{ESN}(221)$ & 0 & $4.1(9)$ & $14(31)$ & $37.6(83)$ & $44.3(98)$ & \\
\hline \multicolumn{8}{|l|}{ Pregnancy related information } \\
\hline \multirow[t]{2}{*}{ Advice on AEDs and pregnancy } & Non-ESN (122) & $9(11)$ & $15.6(19)$ & $18.9(23)$ & $27.9(34)$ & $28.7(35)$ & $10.104(4), p=0.039^{*}$ \\
\hline & $\operatorname{ESN}(121)$ & $2.5(3)$ & $15.7(19)$ & $14(17)$ & $23.1(28)$ & $44.6(54)$ & \\
\hline
\end{tabular}

ns not significant * significant at $p<.05{ }^{* *}$ significant at $p<.01 * * *$ significant at $p<0.001$ 


\begin{tabular}{lcc}
\hline & $\begin{array}{c}\text { Non-ESN } \\
\text { Mean (SD) }\end{array}$ & $\begin{array}{c}\text { ESN } \\
\text { Mean (SD) }\end{array}$ \\
\hline Involvement in care & & \\
I am given opportunity to ask questions & $4.20(.88)$ & $4.44(.72)$ \\
I am given enough time to discuss my worries & $3.91(1.03)$ & $4.24(.93)$ \\
I am involved in all decisions made about my care and treatment & $3.86(1.03)$ & $4.14(.94)$ \\
My wishes and needs are taken into account when my care is planned & $3.89(.93)$ & $4.16(.91)$ \\
If my family or someone else close to me wants to talk, they have the & $3.84(.98)$ & $4.21(.83)$ \\
opportunity to do so & & \\
Total mean score & $3.95(.82)$ & $4.23(.73)$ \\
Co-ordination of care & & \\
My care is delivered in a planned and co-ordinated manner & $3.91(.88)$ & $3.98(.93)$ \\
I find it easy to make an appointment or arrange tests & $3.36(1.27)$ & $3.73(1.06)$ \\
There is good follow-up after my appointment & $3.45(1.24)$ & $3.68(1.09)$ \\
I wait a reasonable amount of time before being seen on each visit & $3.52(1.30)$ & $3.66(1.09)$ \\
Total mean score & $3.57(.88)$ & $3.77(.78)$ \\
\hline
\end{tabular}

